\title{
Radius yanlış kaynaması ile birlikte olan distal radyoulnar eklem instabilitesi
}

\section{Distal radioulnar joint instability with radius malunion}

\author{
Bülent Kılıç, İrfan Ayan \\ Mersin Üniversitesi Tıp Fakültesi, Ortopedi ve Travmatoloji Ana Bilim Dalı, El Cerrahisi Bilim Dalı, Mersin
}

Distal radius kırıklarının uygun olmayan tedavisi sonrası en sık karşılaşılan komplikasyonu yanlış kaynamadır. Distal radiusta, birden fazla planı ilgilendirebilen (sagittal, koronal, aksiyel) yanlış kaynamalar, distal radyoulnar eklemin (DRUE) fonksiyonunu kötü yönde etkiler. Distal radyoulnar eklemin fonksiyonunu bozan mekanizmaların anlaşıması, daha iyi fonksiyonel sonuç elde etme ve tedavi açısından önemlidir. Bu yazıda distal radius kırıklarının tedavisi sonrasında sık karşılaştığımız, yanlış kaynama komplikasyonunun, DRUE üzerine olan bozucu etkileri, tedavi endikasyonları ve yöntemlerine dikkat çekilmesi amaçlanmıştır. Erken yapılması önerilen düzeltici osteotomi kararında sadece radyolojik kriterler değil hasta yaşı, aktivite durumu ve fonksiyonel ihtiyacı ve genel tıbbi durum göz önünde tutulmalıdır.

Anahtar sözcükler: distal radius yanlış kaynama; distal radyoulnar eklem; düzeltici osteotomi
The most common complication of distal radius fractures after improper treatment is malunion. In the distal radius, malunion, which may concern more than one plane (sagittal, coronal, axial), badly affect the function of the distal radioulnar joint. Understanding the mechanisms that disrupt the function of the distal radioulnar joint is important in terms of achieving better functional results and treatment. In this article, it is aimed to draw attention to the destructive effects of malunion complication on distal radioulnar joint, indications and methods of treatment that we often encounter after the treatment of distal radius fractures. Not only radiological criteria, but also patient's age, activity status and functional needs, and general medical condition should be taken into account in the decision on corrective osteotomy, which is recommended to be performed early.

Key words: distal radius malunion; distal radioulnar joint; corrective osteotomy

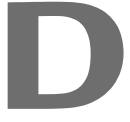
istal radius kırıkları, tüm kırıkların \%12 ila \%17'sini oluşturur. ${ }^{1]}$ Distal radius kırıklarının en sık karşılaşılan komplikasyonu yanlış kaynamadır. Bu komplikasyon cerrahi tedavinin artmasıyla azalmış olup konservatif tedaviyle kötü kaynama oranı \%24 iken cerrahi tedavi ile \%11'e kadar inmiştir. ${ }^{[2,3]}$ Distal radius kırıklarında yanlış kaynama tanımı hala tartışmalıdır. Yanlış kaynamalar her zaman semptomatik değildir ve oluşturduğu semptomlar da deformitenin şiddetiyle uyumlu değildir. ${ }^{[4]}$ Distal radius kırıklarının yanlış kaynamalarında distal radyoulnar eklem (DRUE) anatomisi ve biyomekanik özellikleri değişebilmektedir. Distal radius yanlış kaynamalarında oluşan deformitelerde birden fazla planda zorlayıcı etki genelde beraber bulunmaktadır. Bu yazıda temel olarak distal radius yanlış kaynama modellerinin DRUE üzerine olan zorlayı$\mathrm{Cl}$ etkileri ve tedavisi üzerinde duruldu.

\section{DISTAL RADYOULNAR EKLEM (DRUE) ANATOMI VE BIOMEKANIĞi}

Ulna başı radius distalinde sığ sigmoid çentik ile eklem yapar. Sigmoid çentiğin volar tarafinda $\% 80$ oranında eklem dışı osteofibrokartilaj dudak vardır. Bu dudak ulnanın palmar translasyonuna karşı destek etkisi oluşturarak stabiliteye katkı sağlar..$^{\left[{ }^{3}\right]}$ Sigmoid çentiğin yarıçapı ulna başından daha büyüktür. Distal radyoulnar eklem stabilitesi kemik yapıdan ziyade yumuşak doku ile sağlanmaktadır. Sigmoid çentik ile ulna başı arasındaki maksimum temas \%60 ile nötral pozisyonda olmakta, tam pronasyon ve supinasyonda bu oran \%10'a düşmektedir. ${ }^{[6]}$ Kemik anatominin DRUE stabilitesine katkısı \%30'dur. ${ }^{[7]}$ Distal ulna maksimum pronasyonda $2,8 \mathrm{~mm}$ dorsale, maksimum supinasyonda 5,4 $\mathrm{mm}$ volare translasyon gerçekleştirir. ${ }^{[8]}$

\footnotetext{
- İletişim adresi: Arş. Gör. Uz. Dr. Bülent Kılıç, Mersin Üniversitesi Tıp Fakültesi, Ortopedi ve Travmatoloji Ana Bilim Dalı, El Cerrahisi Bilim Dalı, Mersin Telefon: 0530 - 9000713 e-posta: drbulentkilic@hotmail.com

- Geliș tarihi: 16 Mayıs $2021 \quad$ Kabul tarihi: 5 Haziran 2021
} 


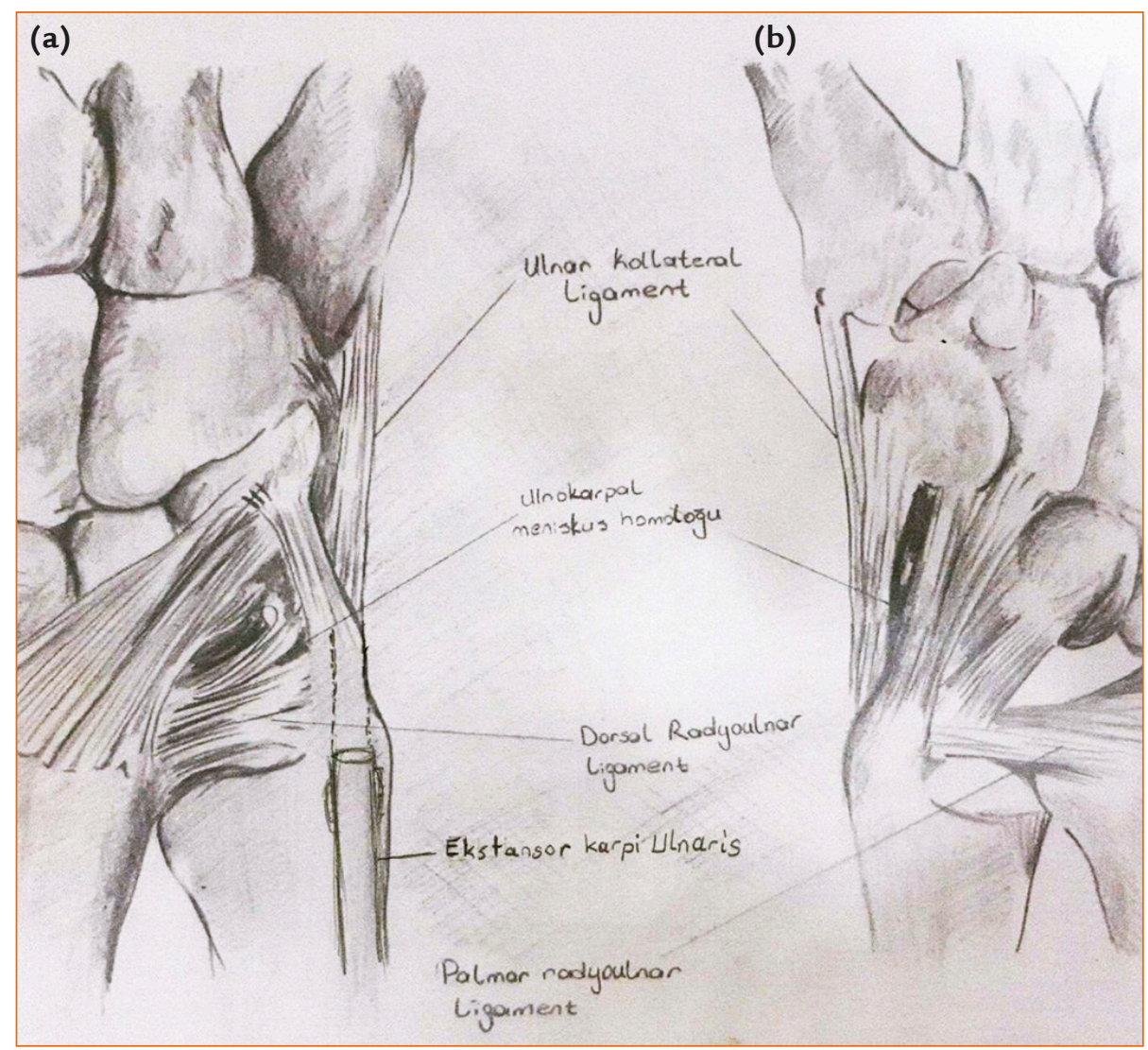

Şekil 1. a, b. Triangular fibrokartilaj kompleks (TFKK) dorsal yüzden (a) ve volar yüzden (b) görünümleri.

Pozitif ulnar varyansta DRUE üzerinde basınç ve yük aktarımı artar. Distal radyoulnar eklemde yumuşak doku stabilitesi primer triangular fibrokartilaj kompleks (TFKK) ile sağlanır. İnterosseöz membran (IOM), ekstansör retinakulum ve pronator kuadratus da eklem stabilitesine yardımcı olan yumuşak doku yapılarıdır. Yine ekstansör karpi ulnarisin (EKU) tendon kılıfı hem dinamik hem statik stabilitede etkilidir. Pronator kuadratus, aktif pronasyonda ve pasif supinasyonda ulna başını sigmoid çentik üzerinde tutarak dinamik stabiliteye katkı sağlar. ${ }^{[9]}$ Ayrıca bir kadavra çalışmasında, DRUE kapsülünün hem maksimum pronasyon hem de maksimum supinasyonda eklem stabilitesine katkısı olduğu gösterilmiştir. ${ }^{[10]}$

Triangular fibrokartilaj kompleksi (TFKK); palmar ve dorsal radyoulnar ligament (RUL), artiküler disk, EKU kılıfı, menisküs benzeri yapı (menisküs homoloğu) ve palmar ulnakarpal bağdan (UKL) oluşur (Şekil 1). Distal radyoulnar eklem stabilitesinde en önemli etkiyi RUL'ler yapmaktadır. Radyoulnar ligamentlerin derin bölümleri foveaya yapışırken yüzeyel bölümleri ulna stiloid orta bölümüne yapışır, bu da distal radius kırık ve kötü kaynamalarında eşlik eden ulna stiloid kırık varlığı ve kırık bölgesinin önemini ortaya koyar.

Transvers plandan incelendiği zaman sigmoid çentiğin dört tipi vardır (Şekil 2). Travma sonrası potansiyel olarak en yüksek instabilite oranı "flat face" olan tiptedir. ${ }^{[5]}$

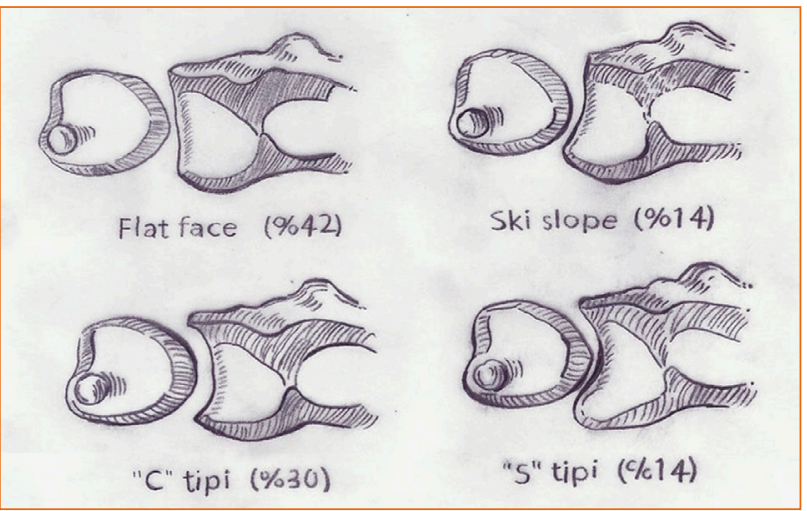

Şekil 2. Transvers planda sigmoid çentik tipleri. 


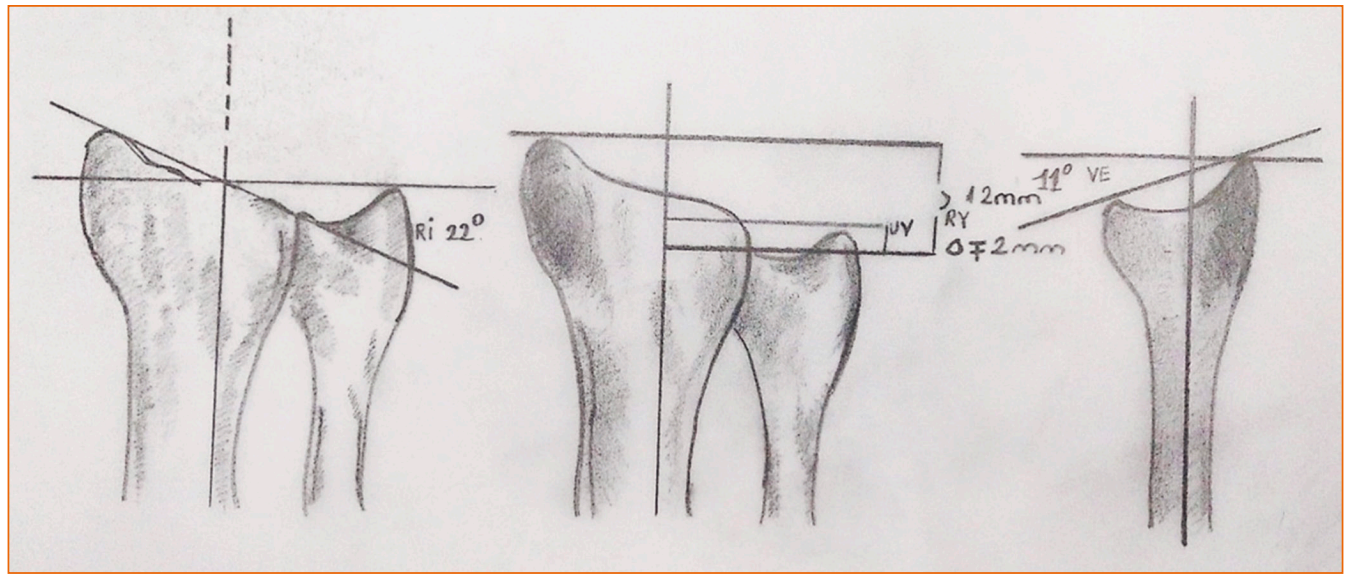

Şekil 3. Distal radius direkt grafilerinde temel açılar (Ri, radyal indeks açısı; UV, ulnar varyans; RY, radyal yükseklik; VE, volar eğim).

\section{DISTAL RADIUS YANLIŞ KAYNAMASI}

Radius distal yanlış kaynama tanımı bugün hala tartışmalıdır. Distal radius yanlış kaynama tanımlanması için direkt grafilerde bakılması gereken temel açı tanımları Şekil 3'te gösterilmiştir. Radyografilerde sağlam tarafla karşılaştırma önemlidir. Radyal yükseklik ortalama $12 \mathrm{~mm}(6-15 \mathrm{~mm})$, volar eğim ortalama $11^{\circ}$ $\left(0^{\circ}-22^{\circ}\right)$, radyal eğim $22^{\circ}\left(15^{\circ}-28^{\circ}\right)$, ulnar varyans $0 \pm 2$ mm'dir.

Bir çalışmada radyal inklinasyon $\leq 15^{\circ}$, dorsal açılanma $\geq 10^{\circ}$, pozitif ulnar varyans $\geq 3 \mathrm{~mm}$ ise yanlış kaynama kabul edilirken [11], bir başka çalışmada ise radyal inklinasyon $<10^{\circ}$, palmar veya dorsal açılanma $>20^{\circ}$, radyal yüksekliğin $<10 \mathrm{~mm}$ olması, pozitif ulnar varyansın $2 \mathrm{~mm}$ 'den büyük olması, eklem yüzünde $2 \mathrm{~mm}$ ve daha büyük basamaklanma ya da gap bulunması yanlış kaynama olarak tanımlanır. ${ }^{[12]}$

Distal radius yanlış kaynamalarında mutlak bir sınıflama olmamakla birlikte ve düzeltici osteotomi yapılması için sadece radyolojik kriterler yeterli olmamasına rağmen, kabul edilemez distal radius kaynama kriterleri şunlardır ${ }^{[12]}$ :

1. Radyal inklinasyonun $<10^{\circ}$ olması

2. Volar eğimin $>20^{\circ}$, dorsal eğimin $>20^{\circ}$ olması

3. Radyal yüksekliğin $<10 \mathrm{~mm}$ olması

4. Ulnar varyansın $>2 \mathrm{~mm}$ olması

5. Eklem içi basamaklanmanın veya gap'in $>2 \mathrm{~mm}$ olması

Amerikan Ortopedik Cerrahlar Derneği, kapalı redüksiyon sonrası dorsal tilt $>10^{\circ}$, radyal kısalık $>3$ $\mathrm{mm}$, eklem içi deplasman $>2 \mathrm{~mm}$ ise, cerrahi tespit önermektedir. ${ }^{[13]}$

\section{Dorsale Açılı Yanlış Kaynamalar}

Ortalama dorsal açılanması $21^{\circ}$ olan bir distal radius yanlış kaynama serisinde rotasyon aksının anlamlı miktarda değişmediği gösterilirken ${ }^{[14]}$, bir başka çalışmada ise distal radiusun $15^{\circ}$ dorsale açılanmasında ön kol rotasyon aksında 3,5 mm'lik kayma oluştuğu tespit edilmiştir. ${ }^{[15]}$ Dorsal açılanma arttıkça ulnokarpal ve radyoskafoid eklemde yük artışı olmaktadır. ${ }^{[16]}$ Bu durum yük dağılımının ulnokarpal ve radyoskafoid eklemlerde konsantre bir şekilde daha dorsale kaymasına neden olmaktadır. Bu da ilgili eklemlerde erken dejeneratif değişikliklere neden olabildiği gibi, ulna stiloid kırığı olmadan da TFKK'de ayrılmaya neden olabilmekte ve $20^{\circ}$ dorsale açlı yanlış kaynamada ön kolda hem pronasyon hem supinasyon azalmaktadır. Dorsal açılanma $20^{\circ}$ üzerine çıktığı zaman DRUE uyumu bozulur, IOM ve IOM'nin bir parçası olan distal oblik demet (bundle) (DOB)'da gerilim artışına neden olarak supinasyon ve pronasyon kısıtlılığı oluşturmaktadır. ${ }^{[17]}$ Yine radiusun dorsal açılanması arttıkça ulnanın volare ve distale deplasmanı artmaktadır. Bu etki $10^{\circ}$ 'lik dorsal açılanmadan sonra başlamaktadır. Ulnadaki volare deplasman, TFKK'nin stabilize edici etkisi aşıldıktan sonra daha da artmaktadır. Ayrıca $15^{\circ}$ dorsal açılanma RUL yaralanmasını \%9 artırır. ${ }^{[18]}$ Distal radyoulnar eklem dinamiğinde, dorsal açılanma sonrası oluşan değişiklikler daha düşük beklentili yaşılıarda ilerleyici klinik semptom vermeyebilir. ${ }^{[19]}$ Ayrıca dorsal açılanma deformitesi, genellikle dorsal translasyon, radyal translasyon, kısalma veya rotasyonla beraber olabilir ve bu durumda DRUE üzerine olan negatif etki izole dorsal açılanmadan daha fazla olmaktadır. Örneğin TFKK intakt olmak kaydıyla $10^{\circ}$ 'lik dorsale açılanma, $10 \mathrm{~mm}$ dorsal translasyonla beraber olunca ya da $20^{\circ}$ dorsale 
açılanma $5 \mathrm{~mm}$ dorsal translasyon ile beraber olursa ciddi pronasyon kaybı olmaktadır. Yine $10^{\circ}$ dorsal angulasyonla beraber $2,5 \mathrm{~mm}$ radyal kısalık da ciddi pronasyon kısıtlılığına yol açmaktadır. ${ }^{[20]}$

\section{Volare Açılanmalı Yanlış Kaynamalar}

El bileğinde ekstansiyon kısıtlılığı, ön kol supinasyonunda azalma, ağrı ve kavrama gücünde azalmaya yol açmaktadır. Supinasyonun azalması omuz eklemi ile kompanse edilemediği için rahatsız edicidir. ${ }^{[21]} 30^{\circ}$ 'lik volar açılanma lunat fossada yük dağılımını dorsale taşıyarak DRUE sertliğini artırmaktadır.

Bir kadavra çalışmasına göre; volare açılı yanlış kaynamaların, DRUE biyomekaniğindeki bozucu etkisi, dorsale açılanmalı yanlış kaynamalardan daha fazladır. Volare açılanmanın fazla olduğu yanlış kaynamada TFKK intakt ise ulnada volar-dorsal translasyon artmaktadır. TFKK kesildiğinde ise bu artış daha fazla olmaktadır. Dorsale translasyondaki bu artış DRUE sertliğini artırıp bozucu etkiyi daha fazla oluşturmaktadır. Triangular fibrokartilaj kompleksi kesildiğinde, ortalama $10^{\circ}$ lik volar eğim artışı, distal ulnayı 1,3 $\mathrm{mm}$ dorsale kaydırırken, $20^{\circ}$ lik volara eğimde bu kayma $2 \mathrm{~mm}$ olmaktadır. Bu oranlar volare açılı yanlış kaynamaların dorsale açılı yanlış kaynamalara göre DRUE kinematiğinde daha fazla bozulmanın olduğunu göstermektedir. Bu çalışmada volare $10^{\circ}$ 'lik eğim artışı TFKK rüptür varlığında bile deformite düzeltici osteotomi ile normal kinematiğin sağlanabileceğini göstermiştir. Ancak volare açılanmanın, volar tranlasyon, radyal translasyon ve kısalıkla beraber olabileceği unutulmamalıdır. Tüm düzeltici osteotomilerde sadece radyolojik kriterler değil hastanın yaşı, aktivite durumu ve fonksiyonel ihtiyacı ve genel tıbbi durum göz önünde tutulmalıdır. ${ }^{[22]}$

\section{Radyal Koronal Translasyon ile Olan Yanlış Kaynamalar}

Çoğu zaman dorsal translasyon, dorsal parçalanma ve radyal kısalıkla beraberdir. Ayrıca geniş radyal koronal translasyonlara ulna stiloid kırıkları sıklıkla eşlik eder. Stiloid kırığı nedeniyle bozulan volar ve dorsal RUL etkisiyle sigmoid çentik ile ulna başı arasındaki ilişki bozulur. Ayrıca DRUE stabilitesini sağlayan bağlarda gerilim azalması olur. Tek başına radyal translasyon varlı̆̆ı, volar eğim, radyal inklinasyon ve ulnar varyans gibi parametreler normal olsa bile instabilite nedeni olabilir. Ortalama $2 \mathrm{~mm}$ 'lik radyal translasyonda dahi aksiyel yüklenme ile distal radyoulnar stabilitede azalma olduğu gösterilmiştir. ${ }^{[23]}$ Koronal planda radyal translasyonlarda, kırık hattı proksimalindeki iOM ve insanların \% 40 'ında bulunan ve DRUE stabilitesinde önemli rol oynayan DOB gevşer.

\section{Pozitif Ulnar Varyans ile Olan Yanlış Kaynamalar}

Radyal kısalığa bağlı ulna uzunluğundaki 2 mm'lik göreceli artış, ulnokarpal eklem yükünü \%42 artırır. ${ }^{[23]}$ Ulna kısaltma osteotomisinin (UKO), radyal uzatmaya göre komplikasyon oranı daha düşük ve daha basit bir işlemdir. ${ }^{[24]}$ Ulna kısaltma osteotomisinde IOM ve DOB daha proksimale kayacağı için DRUE stabilitesi artar. Ulna uzunluğunda göreceli artma, dorsal açılanmalı yanlış kaynama ile beraber olduğu zaman klinik sonuçlar daha kötüdür. ${ }^{[25]}$ Pozitif ulnar varyansla beraber $20^{\circ}$ 'den fazla dorsal açılanma ya da $10^{\circ}$ 'den fazla volar eğim artışı ile birlikte olan kötü kaynamalarda UKO'dan ziyade distal radius düzeltici osteotomisi önerilmesine rağmen ${ }^{[26]}$ başka bir çalışmada da sagittal plan deformitesinin $20^{\circ}$ 'yi geçmediği durumlarda UKO ile açık kama distal radius düzeltici osteotomileri arasında anlamlı fark olmadığı da gösterilmiştir.[27] UKO'da ağrılı kaynamama ile karşılaşılabilmektedir.

Distal radius kötü kaynamasında düzeltici osteotominin semptomatik kötü kaynamanın saptanmasından sonra erken dönemde yapılmasının tavsiye edildiği bir çalışmada yaralanmadan sonraki ilk 14 haftada yapılan osteotomilerde kavrama gücü açısından daha sonra yapılanlara göre anlamlı derecede fark saptanmıştır. ${ }^{[28]}$ Yine bir başka seride de travmadan sonra ortalama 12 hafta içinde yapılan düzeltici osteotomi ile başarılı sonuçlar elde edilmiştir. ${ }^{[29]}$

\section{DÜZELTICi OSTEOTOMI SEÇENEKLERi}

Dorsale açılanmalı yanlış kaynama daha fazla görülmektedir. Bu tip yanlış kaynamada klasik olarak dorsal açık kama osteotomisi ve greft uygulanır. Bu yaklaşımda gerilim tarafına plak uygulanması tespit güvenliğini sağlamaktadır. Ayrıca yeni nesil implantlarla tendon irritasyon ve rüptür oranı azalmaktadır. ${ }^{[4]}$ Dorsal yaklaşımla yapılan açık kama düzeltici osteotomisinden sonra 11 olguluk bir seride implant çıkarmayı gerektirecek olgu olmamıştır. ${ }^{[30]}$ Dorsale açılanmalı yanlış kaynamalarda volar yaklaşımla yapılan osteotomilerde volar korteksin devamlılığının sağlanması kemik grefti kullanımı ihtiyacını ortadan kaldırabildiği gibi sabit açılı volar plak ile kolay ve sağlam tespit elde edilebilir. Ancak sagittal plan deformiteli yanlış kaynamalarda sıklıkla eşlik eden radius kısalığı göz önüne alınmalıdır (Şekil 4).

Volare açılanmalı distal radius yanlış kaynamalarında ise volar yaklaşımla açık kama osteotomisi daha uygundur (Şekil 5). Yirmi sekiz olguluk bir seride volar yaklaşımla açık kama osteotomi, yapısal greft ve sabit açılı kilitli volar plak ile tespit yapılan olguların tamamında kaynama elde edilirken, supinasyonda ortalama $64^{\circ}$ düzelme elde edilmiştir. ${ }^{[20]}$ 

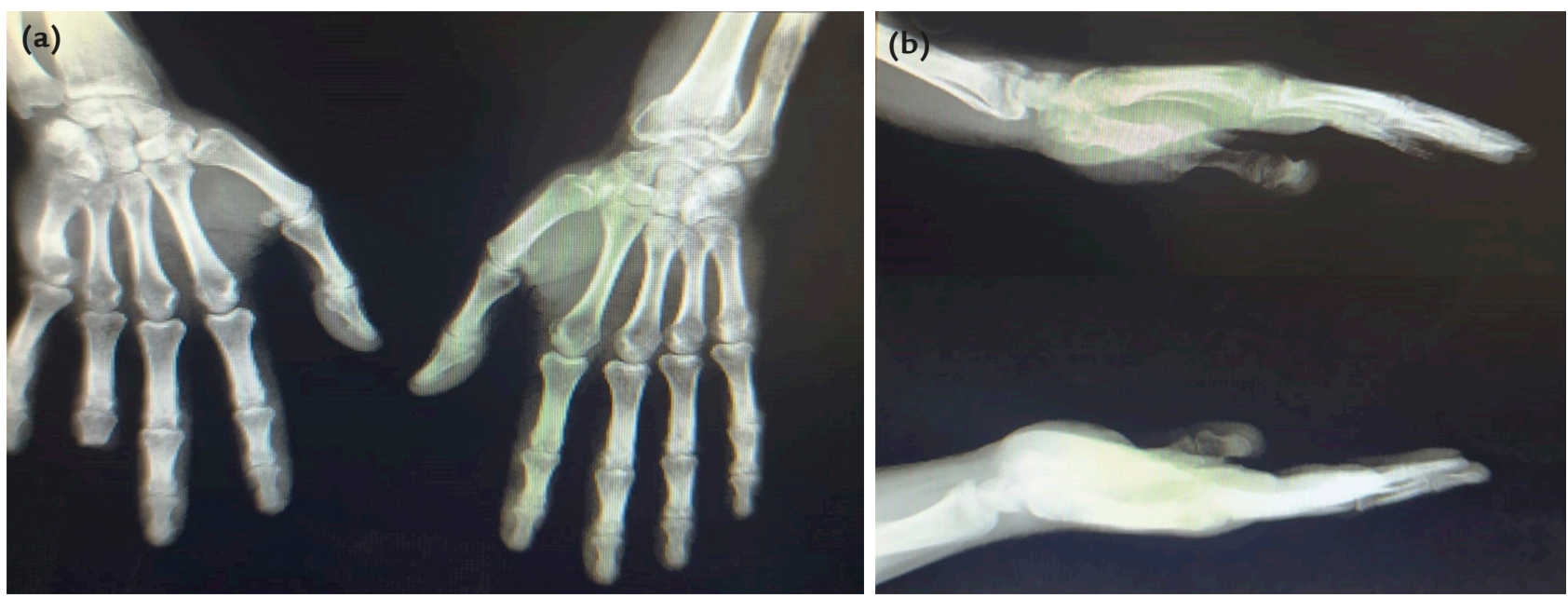

(c)
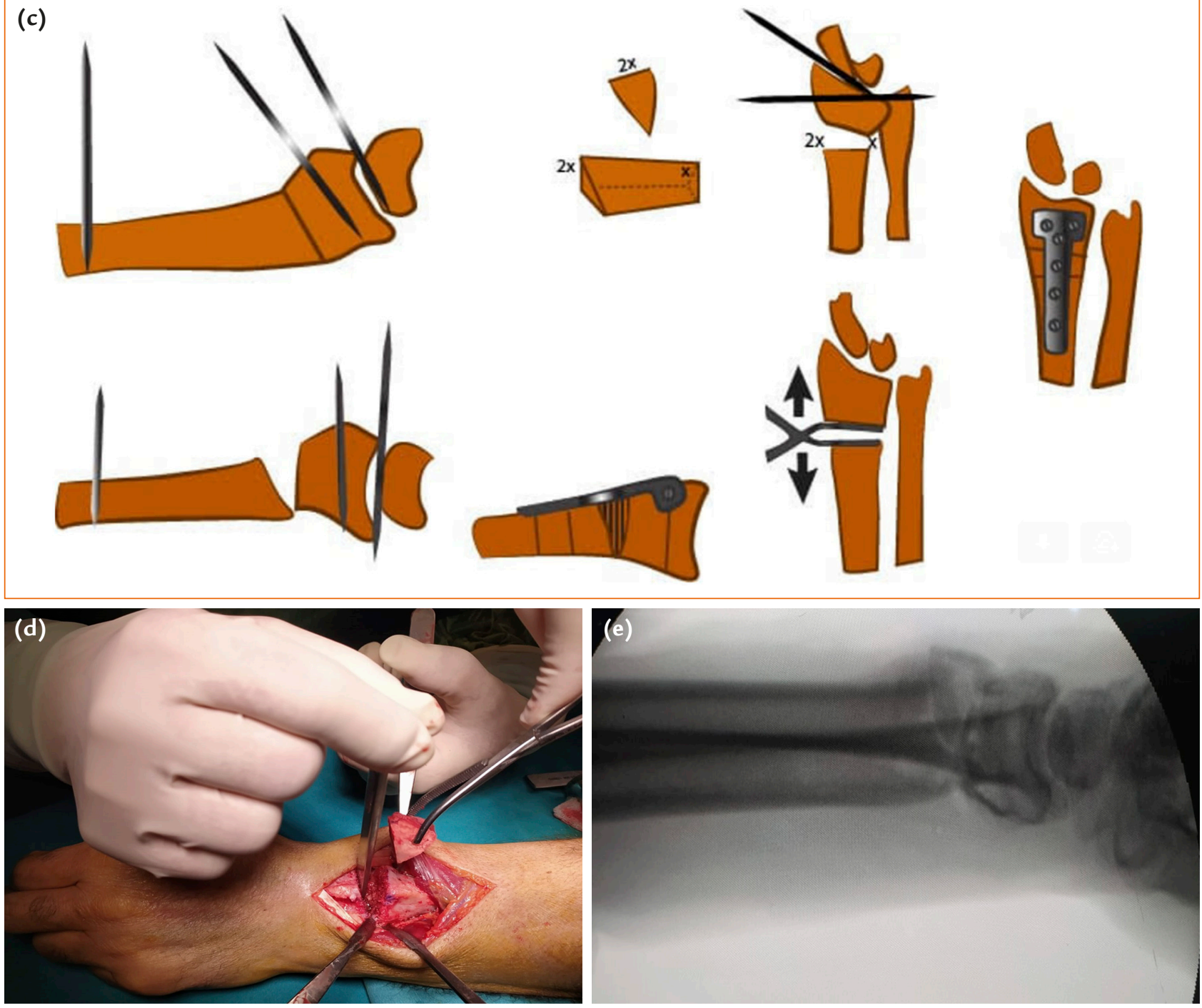

Şekil 4. a-e. Solda ulna stiloid kırığı ile beraber pozitif ulnar varyans oluşturmuş distal radius yanlış kaynaması (a). Yan grafide dorsale açılanmalı yanlış kaynama görülmekte. Hastanın tek bulgusu ağrısız fleksiyon kısıtlılı̆̆ı idi (b). Dorsale açılanmalı yanlış kaynamada dorsalden düzeltici osteotomi, greft yerleştirilmesi ve plak uygulamasının şematik çizimi (c). Dorsal yaklaşımla düzeltici osteotomi yapılan distal radiusa trikortikal greft yerleştirilmesi (d). Ameliyat esnasındaki yan floroskopi görüntüsü (e). 

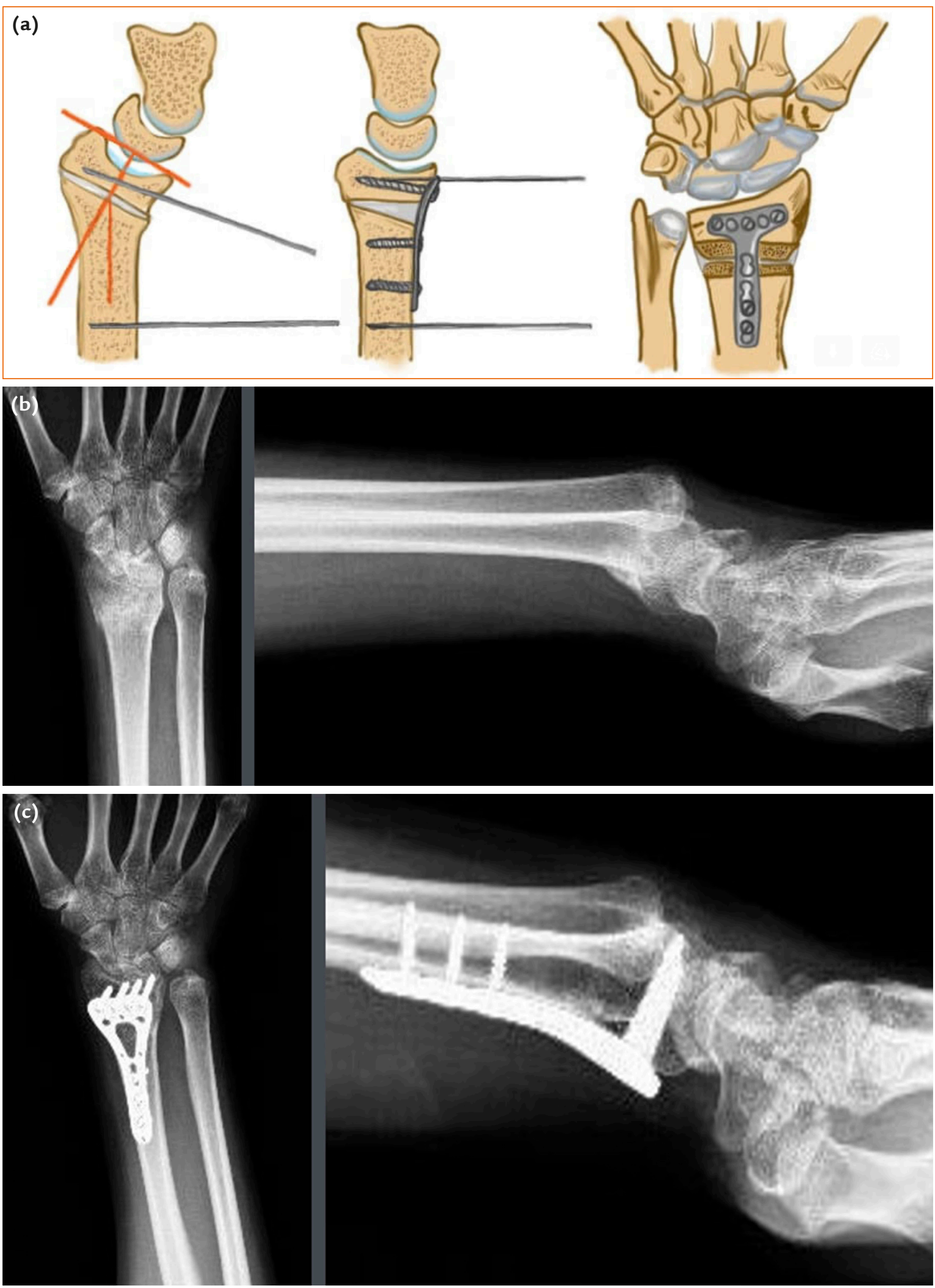

Şekil 5. a-c. Volare açılanmalı yanlış kaynamada volar yaklaşımda yapılan osteotomi, greft yerleştirilmesi ve plak uygulamasının şematik çizimi (a). Arka-ön radyografide radiusta kısalık ve yan radyografide volare açılanmalı yanlış kaynama olan olguda ulnanın dorsalde olan görüntüsü (b). Volar yaklaşımla düzeltici osteotomi, greftleme ve plak uygulanmış olgunun arka-ön ve yan radyografi görüntüsü (c). 
Wada ve ark., yapmış oldukları 42 olguluk bir seride açık kama osteotomi ve yapısal greft ile tespit edilen olgularla kapalı kama osteotomisi ve ulnar kısaltma yapılan olguların sonuçlarını karşılaştırmışlardır. Fleksiyon-ekstansiyon açıklığında kapalı kama osteotomi ve ulnar kısaltma yapılan olgularda daha iyi sonuçlar elde edilmişken, supinasyon-pronasyon açıkığında anlamlı farklar tespit edilmemiştir. Yine gruplar arasında kavrama güçleri açısından anlamlı fark tespit edilemezken Mayo el bilek skorlarında kapalı kama osteotomisi ve ulnar kısaltma yapılan olgularda daha iyi sonuçlar elde edilmiştir. ${ }^{[31]}$

Eklem dışı düzeltici osteotomi yapılan 60 olguluk bir seride enfeksiyon, redüksiyon kaybı ve implant yetmezliği, tendon irritasyonu veya rüptürü, kompleks bölgesel ağı sendromu, sinir yaralanması gibi komplikasyonların oranı \%58 civarında (35 hasta) saptanmış olup, bunların 13'ünde ikincil cerrahi gereksinim olurken $^{[32]}, 122$ olguluk geniş bir seride ise komplikasyon oranı \%12 olarak bildirilmiştir. ${ }^{[33]}$

Sonuç olarak; DRUE instabilitesine yol açan distal radius yanlış kaynamalarında tedavinin kişiye özel olması gerektiği unutulmamalıdır. Distal radyoulnar eklem üzerinde zorlayıcı etki yapacak yanlış kaynamalar genelde birden fazla planda olmaktadır. Literatürde yanlış kaynamaların farklı planlardaki kombinasyonlarını karşılaştıracak geniş seriler yoktur. Düzeltici osteotomi planlanırken yanlış kaynama modellerinin DRUE üzerine zorlayıcı etkileri ayrı ayrı düşünülmelidir. Ayrıca distal radius yanlış kaynaması ile oluşan DRUE instabilitesinde hastanın şikâyetleri, genel sağlık durumu, yaşı, fizyolojik ve sosyal ihtiyaçları göz önüne alınarak tedavi seçeneği planlanmalıdır. Radyolojik kötü kaynama bulguları ile hastanın klinik şikâyetleri arasında doğrudan bir ilişki olmayabileceği, düzeltici osteotomi yapılacaksa da bunun erken aşamada yapılması ile daha iyi sonuç alınacağı unutulmamalıdır.

\section{Teşekkür}

Yazı içindeki şekillerin çizimini yapan, Mersin Üniversitesi Tıp Fakültesi Beyin ve Sinir Cerrahisi Ana Bilim Dalı Öğr. Üyesi Dr. Derya Karataş'a ve ressam Muazzez Yıldızhan'a (Mersin) teşekkür ederiz.

\section{KAYNAKLAR}

1. Nana $A D$, Joshi $A$, Lichtman $D M$. Plating of the distal radius. J Am Acad Orthop Surg 2005;13(3):159-71. Crossref

2. McGrory BJ, Amadio PC. Malunion of the distal radius. In: Cooney WP, Linscheid RL, Dobyns JH, editor. The Wrist: Diagnosis and Operative Treatment. St Louis: CV Mosby; 1998. p.356-84.
3. Sharma $H$, Khare GN, Singh $S$, Ramaswamy AG, Kumaraswamy V, Singh AK. Outcomes and complications of fractures of distal radius ( $A O$ type $B$ and $C$ ): volar plating versus nonoperative treatment. J Orthop Sci 2014;19(4):53744. Crossref

4. Katt B, Seigerman D, Lutsky K, Beredjiklian P. Distal radius malunion. J Hand Surgery Am 2020;45(5):433-42. Crossref

5. Tolat AR, StanleyJK, Trail IA, A cadaveric study of the anatomy and stability of the distal radioulnar joint in the coronal and transverse planes. J Hand Surg Br 1996;21(5):587-94. Crossref

6. Ekenstam FAF, Hagert CG. Anatomical studies on the geometry and stability of the distal radio ulnar joint. Scand J Plast Reconstr Surg 1985;19(1):17-25. Crossref

7. Stuart PR, Berger RA, Linscheid RL, An KN. The dorsopalmar stability of the distal radioulnar joint. J Hand Surg Am 2000;25(4):689-99. Crossref

8. Huang JI, Hanel DP. Anatomy and biomechanics of the distal radioulnar joint. Hand Clin 2012;28(2):157-63. Crossref

9. Stuart PR. Pronator quadratus revisited. J Hand Surg $\mathrm{Br}$ 1996;21(6):714-22. Crossref

10. Watanabe H, Berger RA, An KN, Berglund LJ, Zobit ME. Stability of the distal radioulnar joint contributed by the joint capsule. J Hand Surg Am 2004;29(6):1114-20. Crossref

11. Ali M, Brogren E, Wagner $P$, Atroshi I. Association between distal radial fracture malunion and patient-reported activity limitations. J Bone Joint Surg Am 2018;100(8):633-39. Crossref

12. Haase SC, Chung KC. Management of malunions of the distal radius. Hand Clin 2012;28(2):207-16. Crossref

13. Lichtman DM, Bindra RR, Boyer MI, David M Lichtman, Randipsingh R Bindra, Martin I Boyer, Matthew D Putnam, David Ring, David J Slutsky, John S Taras, William C Watters 3rd, Michael J Goldberg, Michael Keith, Charles M Turkelson, Janet L Wies, Robert $\mathrm{H}$ Haralson 3rd, Kevin M Boyer, Kristin Hitchcock, Laura Raymond. American Academy of Orthopaedic Surgeons Clinical Practice Guideline on: the treatment of distal radius fractures. J Bone Joint Surg Am 2011;93(8):775-78. Crossref

14. Morre DC, Hogan KA, Crisco JJ III, Akelman E, Dasilva MF, Weiss AP. Three-dimensional in vivo kinematics of the distal radioulnar joint in malunited distal radius fractures. J Hand Surg Am 2002;27(2):233-42. Crossref

15. Short WH, Palmer AK, Werner FW, Murphy DJ. A biomechanical study of distal radial fractures. J Hand Surg Am 1987;12(4):529-34. Crossref

16. Kihara H, Palmer AK, Werner FW, Short WH, Fortino MD. The effect of dorsally angulated distal radius fractures on distal radioulnar joint congruency and forearm rotation. J Hand Surg Am 1996;21(1):40-7. Crossref

17. Adams BD. Effects of radial deformity on distal radioulnar joint mechanics. J Hand Surg Am 1993;18(3):492-8. Crossref

18. Nishiwaki M, Welsh M, Gammon B, Ferreira LM, Johnson JA, King GJW. Distal radioulnar joint kinematics in simulated dorsally angulated distal radius fractures. J Hand Surg Am 2014;39(4):656-63. Crossref

19. Fraser GS, Ferreira LM, Johnson JA, King GJW. The effect of multiplanar distal radius fractures on forearm rotation: in vitro biomechanical study. J Hand Surg Am 2009;34(5):83848. Crossref

20. Sato $\mathrm{K}$, Nakamura $\mathrm{T}$, Iwamoto $\mathrm{T}$, Toyoma $\mathrm{Y}$, Ikegami $\mathrm{H}$, Takayama S. Corrective osteotomy for volary malunited distal radius fracture. J Hand Surg Am 2009;34(1):27-33. Crossref 
21. Nishiwaki M, Welsh M, Gammon B, Ferreira LM, Johnson JA, King GJW. Effect of volary angulated distal radius fractures on forearm rotation and distal radioulnar joint kinematics. J Hand Surg Am 2015;40(11):2236-42. Crossref

22. Orbay JL. Ulnar head and styloid fractures. In: Slutsky DJ, editor. Principles and Practice of Wrist Surgery, 1st ed. Philadelphia: Saunders; 2010. p.198-204. Crossref

23. Palmer AK, Werner FW. Biomechanics of the distal radioulnar joint. Clin Orthop Relat Res 1984;(187);26-35. Crossref

24. Hassan S, Shafafy R, Mohan A, Magnussen P. Solitary ulnar shortening osteotomy for malunion of distal radius fractures: experience of a center in the UK and review of the literature. Ann R Coll Surg Engl 2019;101(3):203-7. Crossref

25. Cowie J, Anakwe R, MacQueen M. Factors associated with one-year outcome after distal radius fracture treatment. J Orthop Surg 2015;23(1):24-8. Crossref

26. Prommersberger $\mathrm{KJ}$, Pillukat $\mathrm{T}$, Mühldorfer $\mathrm{M}$, Van Schoonhoven J. Malunion of the distal radius. Arch Orthop Trauma Surg 2012;132(5):693-702. Crossref

27. Aibinder WR, Izadpanah A, Elhassan BT. Ulnar shortening versus distal radius corrective osteotomy in the management of ulnar impaction after distal radius malunion. Hand (N Y) 2018;13(2):194-201. Crossref
28. Jupiter JB, Ring D. A comparison of early and late reconstruction of malunited fractures of the distal end of the radius. J Bone Joint Surg Am 1996;78(5):739-48. Crossref

29. Bilgin SS, Armangil M. Olgunlaşmamış distal radius yanlış kaynamalarının düzeltilmesi. Acta Orthop Traumatol Turc 2012;46(1):30-4. Crossref

30. Tiren D, Vos DI. Correction osteotomy of distal radius malunion stabilised with dorsal locking plates without grafting. Strategies Trauma Limb Reconstr 2014;9(1):53-8. Crossref

31. Wada T, Tatebe M, Ozasa $Y$, Sato O, Sonoda T, Hirata $\mathrm{H}$, Yamashita. Clinical outcomes of corrective osteotomy for distal radial malunion. J Bone Joint Surg Am 2011;93(17):1619-26. Crossref

32. Haghverdian JC, Hsu JWY, Harness NG. Complications of corrective osteotomies for extra-articular distal radius malunion. J Hand Surg Am 2019;44(11):987.e1-9. Crossref

33. Stirling PHC, Oliver WM, Tan HL, Brown DML, Oliver WC, McQueen MM, Molyneux SG, Duckworth AD. Patient-reported outcomes after corrective osteotomy for a symptomatic malunion of the distal radius. Bone Joint 2020;102-B(11):1542-8. Crossref 